\title{
A longitudinal study of risk factors for community-based home help services in Alzheimer's disease: the influence of cholinesterase inhibitor therapy
}

\author{
This article was published in the following Dove Press journal: \\ Clinical Interventions in Aging \\ 19 March 2013 \\ Number of times this article has been viewed
}

\section{Carina Wattmo \\ Elisabeth Paulsson \\ Lennart Minthon \\ Elisabet Londos \\ Clinical Memory Research Unit, Department of Clinical Sciences, Malmö, Lund University, Malmö, Sweden}

Correspondence: Carina Wattmo Memory Clinic, Skåne University Hospital, SE-205 02 Malmö, Sweden

$\mathrm{Tel}+4640335601$

Fax +46 40335657

Email carina.wattmo@skane.se
Background: To investigate the long-term effects of cholinesterase inhibitor (ChEI) therapy and the influence of sociodemographic and clinical factors on the use of community-based home help services (HHS) by patients with Alzheimer's disease (AD).

Methods: This 3-year, prospective, multicenter study included $880 \mathrm{AD}$ patients treated with donepezil, rivastigmine, or galantamine in a routine clinical setting. At baseline and every 6 months, the patients were assessed with several rating scales, including the Mini-Mental State Examination, Instrumental Activities of Daily Living (IADL), and Physical Self-Maintenance Scale. Doses of ChEI and amounts of HHS per week were recorded. Cox regression models were used to predict the time to HHS, and multiple linear regression was used to predict the volume of HHS used.

Results: During the study, 332 patients (38\%) used HHS. Factors that both postponed HHS use and predicted lower amounts of HHS were higher doses of ChEIs, better IADL ability, and living with family. Men, younger individuals, and those with a slower IADL decline showed a longer time to HHS, whereas female sex, a lower cognitive status, or more medications at baseline predicted fewer hours of HHS.

Conclusions: Higher doses of ChEI might reduce the use of HHS, possibly reducing the costs of community-based care. Female spouses provide more informal care than do male spouses, so the likelihood of using HHS is greater among women with AD. The "silent group" of more cognitively impaired and frail elderly AD patients receives less HHS, which might precipitate institutionalization.

Keywords: cognition, activities of daily living, treatment effect, gender, predictors

\section{Introduction}

Alzheimer's disease (AD) is the most common form of dementia ${ }^{1}$ and usually progresses over the course of several years. Patients experience increasing cognitive impairment and a decline in their ability to perform the activities of daily living (ADL). ${ }^{2}$ In the first stage of $\mathrm{AD}$, individuals are often capable of managing on their own. Thereafter, family members are the first to take over the tasks of caregiving and supervision, if possible. Gradually, the need for various forms of formal services increases, including home help services (HHS), meals on wheels, adult day care, and eventually nursing home placement. The cost of the care of patients with AD rises dramatically as the severity of their dementia increases and it poses an enormous challenge to society. ${ }^{3}$ In Sweden, the levels and amounts of medical care and formal services received are based solely 
on the individual's needs, and these costs are predominantly funded by the social security system. ${ }^{4}$ Of the total cost of dementia care, $85 \%$ is directed to community-based services, $10 \%$ to informal care, and $5 \%$ to hospital care. ${ }^{5}$

The first community-based service that arises as the disease progresses is often HHS. A review of home health care that included individuals with various diseases (including AD) and levels of impairment reported that older age, female sex, solitary living, higher education, and lower ADL ability are predictors of contact with and use of a greater volume of home health care. Conflicting results regarding cognitive impairment have been reported. ${ }^{6}$ Communitybased care for demented elderly individuals is assumed to entail considerably more services and to involve special problems, with a high risk of breakdown leading to nursing home placement and an increased burden on family caregivers. $^{7}$ Few previous studies focusing only on AD patients have investigated the potential sociodemographic and clinical variables that could predict the use of HHS or the amount of HHS used. ${ }^{8}$ Furthermore, most previous studies of formal services were cross-sectional and thus offer little insight into the effects of the longitudinal events that can affect HHS use. ${ }^{9}$

Currently, cholinesterase inhibitors ([ChEIs] donepezil, rivastigmine, and galantamine) are the main treatments used for mild to moderate AD. Randomized trials have demonstrated that ChEIs are effective in slowing cognitive and functional decline compared with placebo-treated controls. ${ }^{10}$ Some studies have also shown that ChEI therapy delays admission to nursing homes and that effective doses might enable nursing home placement to be postponed. ${ }^{11,12}$ To the authors' knowledge, there have been no published naturalistic studies of $\mathrm{AD}$ that consider the effects of the various ChEI agents and doses on HHS as the outcome measure. The present long-term study measured the rates of cognitive and functional decline, the evolution of HHS use, and the amount of HHS used over a 3-year period. This may produce a more comprehensive understanding of the potential predictors of HHS use.

It is important for a patient's physician to know whether the type of ChEI agent and the dose administered alter the patient's use of HHS in order to optimize the effects of treatment and to allow the individual to stay in his or her own home for as long as possible. The identification of patients who do not respond to ChEI therapy or who experience more rapid disease progression is important because they might be expected to have a greater need for formal services. ${ }^{13}$ This information is important to social services for planning and the allocation of resources as well as in counseling patients and their relatives about their futures.

The aim of this study was to investigate the long-term effects of ChEI therapy and the influence of sociodemographic and clinical factors on the use of community-based HHS and the amount of HHS used by patients with AD.

\section{Methods}

\section{Study and subjects}

The Swedish Alzheimer Treatment Study (SATS) was undertaken to investigate the long-term effectiveness of ChEI treatments (donepezil, rivastigmine, or galantamine) in a routine clinical setting. The patients' disease progression was evaluated from various clinical and societal perspectives, including their cognitive and ADL abilities, together with their use of community-based services (HHS, adult day care, or nursing home placement). The SATS is a 3-year, openlabel, observational, nonrandomized, multicenter study and has previously been described in detail. ${ }^{14}$ The patients were prospectively recruited from 14 memory clinics located in different areas across Sweden. All 880 SATS participants with baseline Mini-Mental State Examination (MMSE) ${ }^{15}$ scores ranging from 10 to 26 , indicating mild to moderate stages of $\mathrm{AD}$, who were enrolled up until the end of October 2004 were included in this study.

Before inclusion, all patients underwent a thorough clinical examination, including a medical history, physical and neurological examinations, laboratory tests, and cerebral computed tomography (CT), to rule out other causes of dementia. Outpatients aged 40 years and older who received a clinical diagnosis of dementia as defined by the Diagnostic and Statistical Manual of Mental Disorders, Fourth Edition ${ }^{16}$ and possible or probable AD according to the criteria of the National Institute of Neurological and Communicative Disorders and Stroke and the Alzheimer's Disease and Related Disorders Association ${ }^{17}$ were considered for inclusion in the SATS. Furthermore, the patients were required to live in their own homes with or without community-based services at the time of their AD diagnosis, to have a responsible caregiver (generally the spouse or an adult child), and to be assessable with the MMSE test at the start of their ChEI treatment (baseline). Medications other than ChEIs were documented at baseline and allowed during the study (except for memantine), and the date of eventual nursing home placement was recorded as well as the date of and reason for any withdrawal from the SATS.

All patients and/or caregivers gave their informed consent to participate in the study, which was conducted 
according to the provisions of the Helsinki Declaration and approved by the Ethics Committee of Lund University, Lund, Sweden.

The SATS patients were evaluated in a well-structured 3-year follow-up program that assessed cognition, global performance, instrumental and basic ADL abilities, and the amount of service utilization (HHS and adult day care) every 6 months. Trained dementia nurses evaluated the ADL performance and recorded the amounts of services used per week (if any) in an interview with the caregiver. Following inclusion and the baseline assessments, the patients were prescribed ChEIs as a part of the ordinary Swedish health-care system in accordance with the approved product labeling. The patients paid for their own medications according to routine clinical practice. The SATS is an open nonrandomized study, and the choice of ChEI agent and the dose prescribed for each individual patient was left entirely up to his/her physician's discretion and professional judgment.

\section{Outcome measures}

Cognitive ability was evaluated with the MMSE, with scores ranging from 0 to 30 ; a lower score indicated more impaired cognition. The Instrumental Activities of Daily Living (IADL) scale ${ }^{18}$ consists of eight items: ability to use a telephone, shopping, food preparation, housekeeping, ability to do laundry, mode of transportation, responsibility for own medications, and ability to handle finances. Severity was scored per item ( $1=$ no impairment to $3-5=$ severe impairment) for a total range of 8-31 points. Some of the instrumental activities could be sex dependent among the elderly, so a mathematical correction of the sum of the IADL scores was performed to ensure that these activities did not affect the results. The formula used the data from the rated items to estimate a total score within the range of the total IADL scale. ${ }^{12}$ The Physical Self-Maintenance Scale (PSMS) ${ }^{18}$ consists of six items: toilet, feeding, dressing, grooming, physical ambulation, and bathing. Each item was scored on a range of $1=$ no impairment to $5=$ severe impairment, allowing a total range of $6-30$ points.

\section{HHS}

HHS mean that a professional helper comes to the individual's own home to help with daily domestic duties, such as preparing meals, cleaning, washing up, doing the laundry, shopping for necessities, and accompanying the care recipient outside, as well as providing help with administering the prescribed medications, personal hygiene, toilet visits, bathing, dressing, and eating. More advanced medical care or therapy, performed by a registered district nurse, physical therapist, or occupational therapist, is not included nor are transportation services, meals on wheels, or help with managing finances. The amount of HHS provided was defined as the number of hours per week.

The time periods were defined as the actual number of months between the start of the ChEI treatment and each assessment. The individuals who dropped out from the study were censored so that they contributed information only during the time in which they participated in the SATS.

\section{Predictors}

The study was based on the World Health Organization's framework The International Classification of Functioning, Disability and Health, ${ }^{19}$ which is based on health and health-related domains. These domains are classified from the perspective of body functions and structure, the individual (activity and participation), and the environment (eg, societal). In the statistical models, the independent variables were classical risk factors, such as age at onset of AD (clinician's estimate) and age at the start of ChEI treatment, sex, years of education, the genetic risk factor (the presence of the apolipoprotein E [APOE] $\varepsilon 4$ allele), solitary living (yes/no), the number of medications at baseline, and specific medication use (antihypertensive/cardiac therapy, nonsteroidal antiinflammatory drugs [NSAIDs]/acetylsalicylic acid, antidepressants, antipsychotics or anxiolytics/sedatives/hypnotics). The impact of ChEI treatment was analyzed using different drug agents and doses. According to the results of the clinical dementia examination, cognitive, instrumental, and basic ADL abilities at baseline and at the subsequent assessments and the rates of change in cognition and function per month were also included in the models to provide measures of the severity of $\mathrm{AD}$ and its rate of progression.

The rates of cognitive and functional change were calculated as the changes in the scores from baseline to the patient's last assessment, divided by the number of months between these assessments. To facilitate comparisons of these rates in terms of the MMSE, IADL, and PSMS scores, the changes in these scores were converted to positive values, indicating improvement, or negative values, indicating decline.

The ChEI dose could vary for an individual patient during the treatment period and between patients. Therefore, the mean dose used during the study was calculated for each patient. To obtain a similar metric of percentage of the maximum recommended dose for the three ChEI drugs, the mean dose was divided by the maximum recommended dose 
for each drug, ie, $10 \mathrm{mg}$ donepezil, $12 \mathrm{mg}$ rivastigmine, and $24 \mathrm{mg}$ galantamine. The ChEI agents were coded as a set of dummy variables.

Finally, some biologically plausible interaction effects among the sociodemographic variables (sex, age, and solitary living) and cognitive and functional abilities at baseline were included in the analysis. The term "type of ChEI $\times$ dose" was also included.

\section{Statistical analyses}

The IBM Statistical Package for the Social Sciences (SPSS) software (v 20.0; IBM Corporation, Armonk, NY, USA) was used to perform the statistical analyses. The level of significance was defined as $P<0.05$, if not otherwise specified.

Parametric tests were used because of the large sample and the approximately normally distributed continuous potential predictors. The independent-samples $t$-test was used to compare the differences between the means for the users of HHS and the other patients and between the groups with different sociodemographic and clinical characteristics. The $\chi^{2}$ test was used for the analysis of categorical variables.

Kaplan-Meier graphs were used to illustrate the differences in time to HHS in terms of the categorical variables: "sex $\times$ solitary living" and dose of ChEI. The distribution of time was compared using the log-rank test.

Cox proportional hazards models with backward stepwise elimination were used to separately estimate the effects of different risk factors on the relative risk of time to HHS. Univariate Cox regression analyses were performed with adjustment for the potentially confounding baseline sociodemographic variables of sex, age, and solitary living. A multivariate Cox model was then used to simultaneously estimate the effects of all the candidate predictors and interaction terms on the time to HHS. The hierarchical principle was observed in these analyses; variables were not considered for elimination if they appeared in interactions. Variables with $P>0.05$ were removed from the stepwise models.

The assumption of proportional hazards was tested with log-minus-log plots for the categorical covariates and with time interaction tests (the interaction term between the covariate and time was added to the model and generated a regression coefficient not significantly different from zero) for the time-dependent variables. No violation of the assumption of proportional hazards was detected.

A multiple linear regression model was used to estimate independently the effects of the previously described predictors on the amount of HHS used per week. Collinearity analyses of the variables included in the regression model showed no sign of multicollinearity, which is the undesirable situation in which one independent variable is a linear function of other predictors. The model assumptions were controlled by residual analysis.

\section{Results}

\section{Users versus nonusers of HHS}

Of the 880 AD patients, 332 (38\%) used HHS during the study. The sociodemographic and clinical characteristics of the patients, divided into users and nonusers, are shown in Table 1. The users of HHS were more often female and living alone and used more antidepressant and antipsychotic medications. They were also significantly older at the onset of $\mathrm{AD}$ and at the start of ChEI therapy and had a lower level of education. At baseline, cognitive and functional impairment was greater among the HHS users and they used a greater number of medications. The APOE genotype, specific concomitant medications (antihypertensives/cardiac therapy, NSAIDs/acetylsalicylic acid, anxiolytics/sedatives/ hypnotics), and the mean ChEI dose during the study did not differ between the two groups. No difference in the ChEI dose was detected between the sexes or between the patients living alone or not.

\section{Time to HHS during the study}

The median time from the start of ChEI treatment (shortly after the time of AD diagnosis) to HHS was 6 months. Kaplan-Meier analyses of the distribution of the time from the start of treatment to HHS showed differences between the sexes $(P<0.001)$ and between solitary-living patients and those not living alone $(P<0.001)$. The median time from baseline to HHS was 9.5 months for men versus 6 months for women and 0 months (ie, median = had home help at the start of ChEI therapy) for individuals living alone versus 13 months for those living with a spouse or relative. The interaction term sex $\times$ solitary living was also analyzed and showed a significant difference $(P<0.001)$ for all pairwise comparisons, except for the combination of men living alone and women living alone (Figure 1). The solitary-living patients, regardless of sex, had a median time of 0 months to HHS compared with those not living alone (18 months for men and 12 months for women).

The Kaplan-Meier analysis showed a significant difference between individuals receiving a low or a high dose of ChEI during the study $(P=0.001$; Figure 2$)$. The median cutoff values for the ChEI dose were donepezil $6.9 \mathrm{mg}$, rivastigmine $6.0 \mathrm{mg}$, and galantamine $16.0 \mathrm{mg}$. The patients who received a high dose of ChEI showed a longer median 
Table I Demographic and clinical characteristics of users and nonusers of home help services during the study $(n=880)$

\begin{tabular}{|c|c|c|c|}
\hline \multirow[t]{2}{*}{ Variable } & \multirow{2}{*}{$\begin{array}{l}\text { Users of home help services } \\
(\mathrm{n}=332 / 38 \%) \\
\mathrm{n} / \%\end{array}$} & \multirow{2}{*}{$\begin{array}{l}\text { Nonusers of home help services } \\
(\mathrm{n}=548 / 62 \%) \\
\mathrm{n} / \%\end{array}$} & \multirow[t]{2}{*}{$P$} \\
\hline & & & \\
\hline Female sex & $260 / 78 \%$ & $294 / 54 \%$ & $<0.001$ \\
\hline Carrier of APOE $\varepsilon 4$ allele $(n=860)$ & $228 / 71 \%$ & $361 / 67 \%$ & 0.288 \\
\hline Solitary living at baseline & $212 / 64 \%$ & $91 / 17 \%$ & $<0.00$ I \\
\hline Antihypertensives/cardiac therapy & $131 / 39 \%$ & $211 / 39 \%$ & 0.831 \\
\hline NSAIDs/acetylsalicylic acid & $104 / 31 \%$ & $154 / 28 \%$ & 0.322 \\
\hline Antidepressants & $102 / 31 \%$ & $113 / 21 \%$ & 0.001 \\
\hline Antipsychotics & $25 / 8 \%$ & $15 / 3 \%$ & 0.001 \\
\hline \multirow[t]{2}{*}{ Anxiolytics/sedatives/hypnotics } & $56 / 17 \%$ & $70 / 13 \%$ & 0.112 \\
\hline & Mean \pm SD (range) & Mean \pm SD (range) & $P$ \\
\hline Estimated age at onset, years & $73.6 \pm 7.0(48-87)$ & $7 I .1 \pm 7.4$ (45-87) & $<0.001$ \\
\hline Age at first assessment, years & $76.9 \pm 6.5(52-88)$ & $74.0 \pm 7.1(47-88)$ & $<0.001$ \\
\hline Education, years & $9.1 \pm 2.2(7-17)$ & $9.6 \pm 2.6(7-17)$ & 0.002 \\
\hline MMSE score at baseline & $20.7 \pm 3.8(10-26)$ & $21.7 \pm 3.7(10-26)$ & $<0.001$ \\
\hline IADL score at baseline & $17.5 \pm 5.4(8-3 \mid)$ & $15.3 \pm 5.5(8-29)$ & $<0.001$ \\
\hline PSMS score at baseline & $8.2 \pm 2.7(6-21)$ & $7.2 \pm 1.8(6-16)$ & $<0.001$ \\
\hline Number of medications at baseline & $3.2 \pm 2.6(0-12)$ & $2.6 \pm 2.2(0-10)$ & 0.002 \\
\hline \multicolumn{4}{|c|}{ Mean dose of ChEI during the follow-up period } \\
\hline Donepezil $(n=5 \mid 8)$ & $6.9 \pm 1.8(2.8-9.4)$ & $6.9 \pm 1.7(2.8-9.4)$ & 0.977 \\
\hline Rivastigmine $(\mathrm{n}=198)$ & $6.2 \pm 2.0(2.5-10.5)$ & $6.1 \pm 2.2(2.2-10.5)$ & 0.835 \\
\hline Galantamine $(n=164)$ & $15.8 \pm 3.3(8.0-21.5)$ & $16.4 \pm 3.7(8.0-22.0)$ & 0.297 \\
\hline
\end{tabular}

Abbreviations: APOE, apolipoprotein E; ChEl, cholinesterase inhibitor; IADL, Instrumental Activities of Daily Living scale; MMSE, Mini-Mental State Examination; NSAIDs, nonsteroidal anti-inflammatory drugs; PSMS, Physical Self-Maintenance Scale; SD, standard deviation.

time to HHS (7.5 months) than those who received a lower dose (5.5 months).

\section{Univariate Cox regression models}

Univariate Cox proportional hazards modeling suggested that several risk factors were associated with the time to HHS. A shorter time to HHS was associated with female sex, solitary living, younger age at onset, older age at baseline, lower cognitive and ADL abilities at baseline, faster rate of cognitive and functional decline, treatment with antidepressants or antipsychotics, larger number of medications, lower dose of ChEI, and treatment with donepezil or rivastigmine. The hazard ratios with their 95\% confidence intervals (CIs) and the P-values for these variables are listed in Table 2.

At the start of ChEI therapy, the instrumental ADL scores varied between the three treatment groups. The galantamine-treated patients exhibited better function (mean \pm standard deviation [SD], IADL score of $14.6 \pm 5.4)$ than those treated with donepezil $(16.8 \pm 5.6)$ or rivastigmine $(15.5 \pm 5.3, P<0.001)$. After controlling for baseline IADL abilities in the Cox univariate type of ChEI model, no significant difference was found in the time to HHS among the patients treated with each specific $\operatorname{drug}(P=0.278)$.

\section{Multivariate Cox regression models}

When subjected to multivariate backward elimination modeling, only six of the variables noted above from the univariate analyses were retained in the model together with one of the simultaneously added interaction terms (Table 2). These variables were sex, solitary living, dose of ChEI, age at baseline, IADL score at baseline, rate of change in the IADL score per month, and the interaction effect sex $\times$ solitary living. The following interaction terms were not significant: age $\times$ sex or solitary living, MMSE score $\times$ ADL ability, or type of ChEI $\times$ dose.

The effects of sex and living status should not be interpreted separately because they show an interaction effect. For men living with a spouse or another relative, the hazard ratio for the time to HHS was 1.0 compared with 2.72 for women not living alone; for solitary-living men the hazard ratio was 12.95 versus 13.90 for women living alone.

\section{Amount of HHS during the study}

At baseline, 139 (16\%) of the patients received HHS, with a mean $\pm \mathrm{SD}$ of $5.7 \pm 5.0$ hours per week. Men received a greater number of hours per week $(7.6 \pm 5.9)$ than women (5.2 $\pm 4.6, P=0.041)$. No sex-based differences in age, cognitive or functional impairment, or number of medications at the start of ChEI therapy were observed among the 


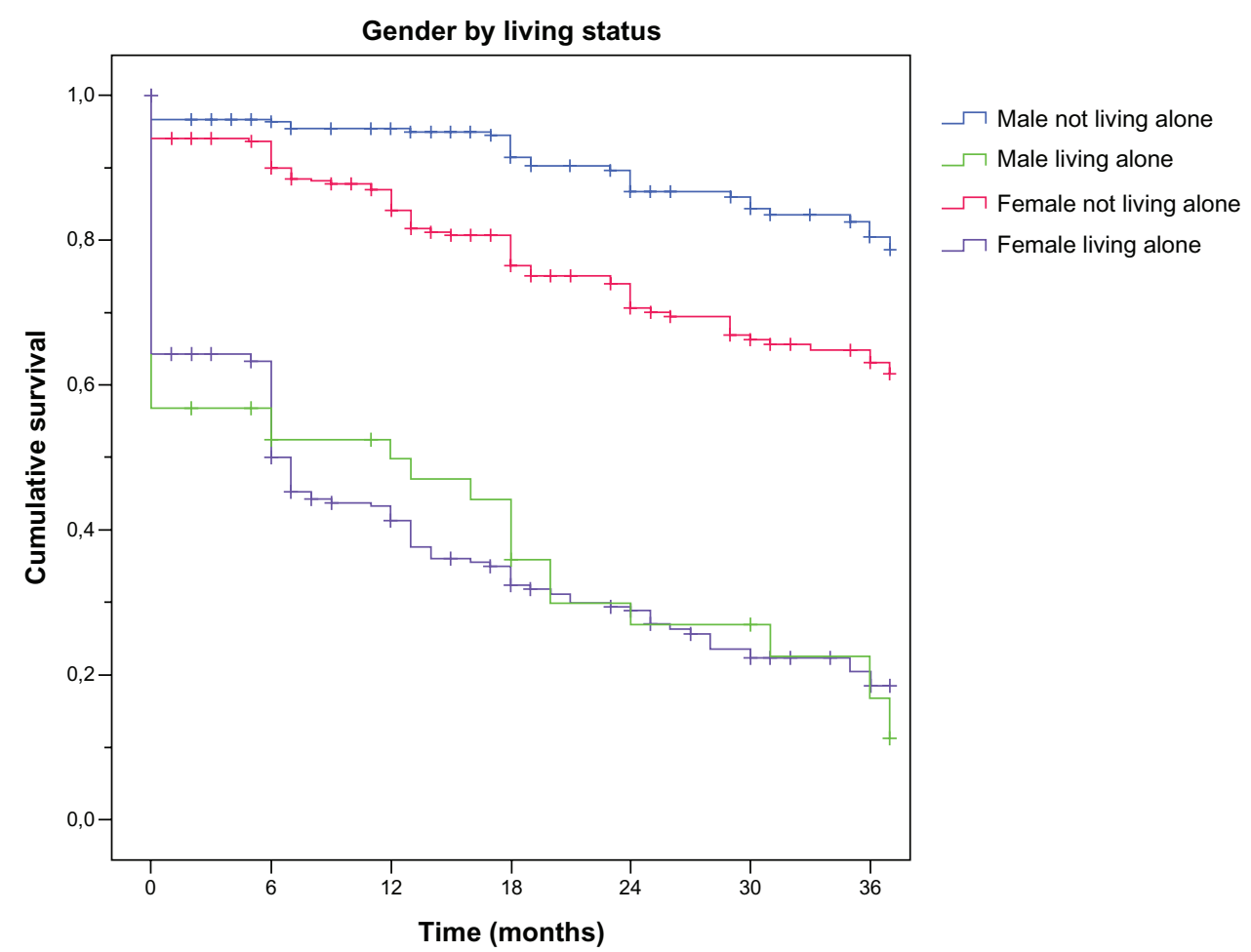

Figure I Kaplan-Meier graph of the distribution of time from the start of ChEl treatment to HHS for the interaction term "sex $\times$ solitary living." Notes: A log-rank test demonstrated a significant difference $(P<0.00 \mathrm{I})$ for all pairwise comparisons, except for the combination of men living alone-women living alone. Abbreviations: $\mathrm{ChEl}$, cholinesterase inhibitor; HHS, home help services.

HHS users. After 3 years, $31 \%$ of the remaining 286 patients living at home used a mean of $8.7 \pm 6.6$ hours of home help per week, with no sex-based difference.

In total, the 332 patients using HHS provided 925 observation points during the 3 -year study. Table 3 shows a multiple regression model $\left(\mathrm{R}=0.436, \mathrm{R}^{2}=0.190\right.$, $P<0.001$ ) with the amount of HHS (hours per week) as the dependent variable. Fewer hours of HHS were associated with female sex, living with a family member, shorter time from the start of ChEI treatment, lower cognitive or higher ADL ability at the corresponding assessment, greater number of medications at baseline, and higher dose of ChEI. The unstandardized $\beta$ coefficients (with their 95\% CIs and $P$-values) for the significant independent predictors are listed in Table 3. As an example, assume that the patients received $100 \%$ of the maximum recommended ChEI dose instead of the mean $65 \%$ observed in the SATS; the regression model would estimate 43 minutes less HHS per week (Figure 3). The arbitrary example presented in the figure is based on an average solitary-living woman who had an MMSE score of 21, IADL score of 17, and PSMS score of 8 at the assessment points and was taking three medications at baseline.

\section{Discussion}

In this long-term study of $\mathrm{AD}$, we found that the dose of ChEI but not the specific drug used was an important predictor of both the time to HHS and the volume of HHS used, after adjustments were made for multiple factors previously shown to be important. A higher IADL ability at the start of the ChEI treatment or a slower rate of IADL decline but not the corresponding cognitive measures might postpone the use of HHS by patients with AD. Men showed a longer time to HHS than women, and the difference was larger for individuals living with family. Women also received fewer hours per week of HHS than men. Lower cognitive ability and a greater number of medications at baseline were also associated with fewer hours of HHS.

The present study is the first to investigate the effects of ChEI therapy on HHS use. For AD patients who could tolerate a higher dose of ChEI, the average time to HHS was prolonged by 2 months and the amount of weekly HHS was also reduced. Theoretically, if we suppose that the patients received $100 \%$ of the maximum recommended ChEI dose (instead of the mean $65 \%$ observed in the SATS), our regression model would on average estimate 43 minutes less HHS per week. This corresponds to about 37 hours per year and 


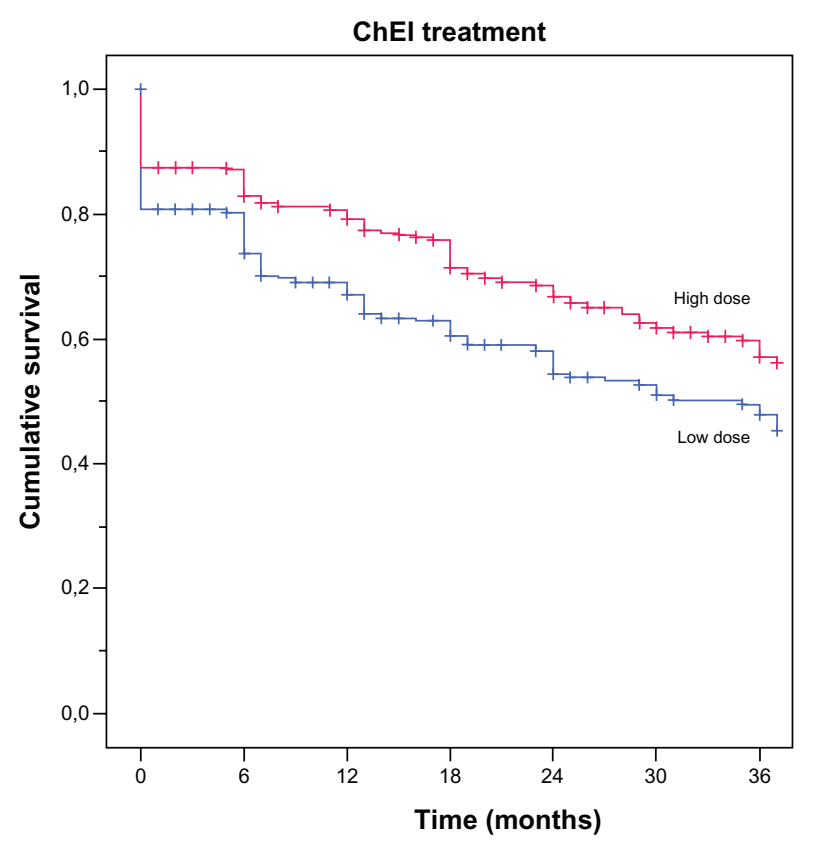

Figure 2 Kaplan-Meier graph of the distribution of time from the start of ChEI treatment to HHS for the variable "ChEl dose."

Notes: A log-rank test showed a significant difference between high versus low doses $(P=0.00 \mathrm{I})$. The cut-off median values for the drug doses were donepezil $6.9 \mathrm{mg}$, rivastigmine $6.0 \mathrm{mg}$, and galantamine $16.0 \mathrm{mg}$.

Abbreviations: $\mathrm{ChEl}$, cholinesterase inhibitor; HHS, home help services.

an annual cost reduction of $\sim 16,200$ SEK ( 2600 USD) per care recipient, ie, $\sim 14.2$ million SEK ( $\sim 2.3$ million USD) for the 880 patients in this study. ${ }^{20}$ In the multivariate models, previously known strong predictors of HHS use, such as age, sex, solitary living, years of education, and performance of $\mathrm{ADL}$, as well as the inconsistent predictor cognitive status, have been taken into account. ${ }^{6} \mathrm{ChEI}$ therapy can be effective for several years in $\mathrm{AD}$ patients, and higher doses might enhance its effects. These findings have been reported in both extension studies originating from randomized placebocontrolled trials ${ }^{21-23}$ and in observational long-term studies of ChEIs. ${ }^{14,24} \mathrm{~A}$ postponed time to nursing home placement was also observed in some studies ${ }^{11,12,25}$ but not in all. ${ }^{26}$ A treatment that has been shown to slow the deterioration in cognitive, global, and functional abilities in AD patients should lead to a reduction in their use of community-based services and the cost of their care.

In this study men living with a spouse or another family member showed an average time to HHS of 18 months compared with 12 months for women not living alone. The 6-month gap between the sexes is presumably covered by the informal care provided by female spouses because they are usually willing to assume a caregiving role longer than are men. ${ }^{27}$ The social services system might also be less responsive to the needs of female caregivers for formal help because it is assumed that they can manage by themselves, particularly regarding IADL. Alternatively, women might be less accepting of services that help with household chores in their homes. ${ }^{28}$ Today, most women are employed outside the home, often full-time, which implies that the potential time available to provide care for family members is reduced. Younger generations of women may instead use formal help to compensate for the limited time available for caregiving because of their work and other commitments. Therefore, the demand and need for resources from social services might increase. However, most spouses of $\mathrm{AD}$ patients have passed their retirement age. ${ }^{29}$ The present study also shows that the likelihood of HHS usage was almost threefold higher for women living with a spouse or relative than for men in the same situation. A considerable number of earlier studies of service utilization have investigated the main effects of critical predictors, such as sex and solitary living or marital status, but hardly any have analyzed the potential interactions between these factors. Studies of the time to nursing home placement that evaluated this interaction effect showed that men living alone had the highest risk of early admission. ${ }^{12,30}$

Our study showed that IADL capacity at the start of ChEI treatment and its subsequent rate of decline are stronger predictors of the time to HHS than the corresponding cognitive measures, even in $\mathrm{AD}$ patients. This result is consistent with recent studies that have shown that functional impairment, independent of cognitive status, precipitated nursing home placement in $\mathrm{AD}$ patients. ${ }^{12,31}$ A review of the use of home health care that included individuals with various diseases reported that a high number of ADL/IADL impairments was a strong predictor of both contact with formal care and the volume of HHS used. Inconsistent results regarding cognitive impairment have also been observed. ${ }^{6}$ In a study of demented elderly people, cognitive status was significantly related to formal personal care but not to homemaking, in-home nursing, or meals on wheels. Because these individuals may exhibit agitated behavior when receiving help with personal hygiene, family members might be reluctant to provide such care. ${ }^{32}$ Although HHS may meet the needs of demented care recipients by helping them regarding their functional impairments, it does not directly address other needs related to cognitive deterioration, such as surveillance, diversion from repetitive or dangerous activities, and management of behavioral disturbances. ${ }^{32,33}$

The findings of the current naturalistic AD study that lower cognitive ability and a greater number of 
Table 2 Cox proportional hazards modeling of time to home help services

\begin{tabular}{|c|c|c|c|c|}
\hline & \multicolumn{2}{|l|}{ Univariate $^{\mathrm{a}}$} & \multicolumn{2}{|c|}{ Multivariate, significant predictors } \\
\hline & Hazard ratio $(95 \% \mathrm{Cl})$ & $\boldsymbol{P}$ & Hazard ratio $(95 \% \mathrm{Cl})$ & $\boldsymbol{P}$ \\
\hline Sex $($ male $=0$, female $=I)$ & $1.54(1.17-2.04)$ & 0.002 & $2.72(1.82-4.06)$ & $<0.001$ \\
\hline Carrier of APOE $\varepsilon 4$ allele $($ no $=0$, yes $=I$ ) & $1.09(0.85-1.39)$ & 0.504 & & \\
\hline Solitary living at baseline $($ no $=0$, yes $=I$ ) & $4.4 \mid(3.45-5.63)$ & $<0.001$ & $12.95(7.82-2 \mid .44)$ & $<0.001$ \\
\hline Interaction: sex $\times$ solitary living & & & $0.39(0.22-0.69)$ & 0.001 \\
\hline \multicolumn{5}{|l|}{ Type of ChEl ${ }^{b}$} \\
\hline Rivastigmine & $0.89(0.66-1.19)$ & 0.421 & & \\
\hline Galantamine & $0.70(0.52-0.96)$ & 0.024 & & \\
\hline ChEl dose ${ }^{c}$ & $0.993(0.987-0.999)$ & 0.033 & $0.993(0.987-0.999)$ & 0.040 \\
\hline Antihypertensives/cardiac therapy & $1.09(0.87-1.37)$ & 0.458 & & \\
\hline \multicolumn{5}{|l|}{$($ no = 0, yes $=1)$} \\
\hline NSAIDs/acetylsalicylic acid (no $=0$, yes $=I$ ) & $1.05(0.83-1.33)$ & 0.700 & & \\
\hline Antidepressants $($ no $=0$, yes $=1$ ) & $1.33(1.05-1.69)$ & 0.017 & & \\
\hline Antipsychotics (no $=0$, yes $=1$ ) & $1.85(1.22-2.81)$ & 0.004 & & \\
\hline Anxiolytics/sedatives/hypnotics & $1.10(0.82-1.47)$ & 0.516 & & \\
\hline \multicolumn{5}{|l|}{$($ no $=0$, yes $=1)$} \\
\hline Estimated age at onset, years & $0.96(0.93-0.999)$ & 0.046 & & \\
\hline Age at first assessment, years & $1.05(1.03-1.07)$ & $<0.001$ & $1.02(1.00-1.04)$ & 0.045 \\
\hline Education, years & $0.96(0.92-1.01)$ & 0.121 & & \\
\hline MMSE score at baseline & $0.91(0.89-0.94)$ & $<0.001$ & & \\
\hline IADL score at baseline & $1.12(1.09-1.14)$ & $<0.001$ & $1.14(1.11-1.16)$ & $<0.001$ \\
\hline PSMS score at baseline & $1.18(1.13-1.22)$ & $<0.001$ & & \\
\hline MMSE score, rate of change per month & $0.82(0.7 \mathrm{I}-0.94)$ & 0.006 & & \\
\hline IADL score, rate of change per month & $0.55(0.36-0.83)$ & 0.005 & $0.34(0.23-0.5 \mathrm{I})$ & $<0.001$ \\
\hline PSMS score, rate of change per month & $0.68(0.57-0.8 I)$ & $<0.001$ & & \\
\hline Number of medications at baseline & $1.07(1.03-1.12)$ & 0.002 & & \\
\hline
\end{tabular}

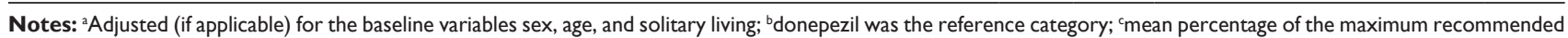
dose, ie, $10 \mathrm{mg}$ of donepezil, $12 \mathrm{mg}$ of rivastigmine, or $24 \mathrm{mg}$ of galantamine. Hazard ratios are expressed per I unit increase for continuous variables and for the condition present for categorized variables.

Abbreviations: APOE, apolipoprotein E; ChEl, cholinesterase inhibitors; Cl, confidence interval; IADL, Instrumental Activities of Daily Living scale; MMSE, Mini-Mental State Examination; NSAIDs, nonsteroidal anti-inflammatory drugs; PSMS, Physical Self-Maintenance Scale.

medications at baseline are related to a smaller volume of HHS are alarming. The social service system may be more focused on functional capacity than on cognitive ability because deficiencies in ADL are more visible and easier to compensate. Moreover, care recipients with a higher cognitive status are presumably better able to communicate their needs and to request more help from community-based services. Individuals with more severe cognitive impairment may be reluctant to accept the offered assistance or may refuse help or may be unwilling to cooperate with home help staff, which presumably reduces the amount of formal services available to them. ${ }^{28}$ Frail elderly care recipients with multiple diseases might be bedridden to a greater extent than healthier individuals, so assistance with some ADL (eg, going out for a walk) is no longer provided. Economic cutbacks have led to less formal help with IADL and a greater focus on personal care. ${ }^{34}$ However, more formal services may be given to assertive care recipients or caregivers and those who are more vocal in requesting additional help. ${ }^{28}$ In summary, this implies that individuals who are more cognitively impaired and the frail AD patients with multimorbidity might be at risk of having their needs unmet.

Since the early 1990s the formal care and services for older people in Sweden have been transferred from special housing accommodation to the individual's own home. It is assumed that it is best for the elderly to remain at home. Consequently, those cared for at home have a poorer health status today and a greater need for care than was previously the case. The Swedish welfare state assures individuals the right to publicly funded necessary care, with no obligation on the family. The type and volume of community-based services required are assessed according to the care recipient's impairment in a similar way across the social service system, regardless of the municipality. ${ }^{4}$ Conversely, in some countries, such as the United States, the use of home health care is affected by the individual's level of education, income, and health insurance. ${ }^{6}$ The HHS reported in the present study reflects the care recipients' actual needs for formal care, irrespective of socioeconomic factors. 
Table 3 Factors affecting the amount of home help services (hours per week)

\begin{tabular}{|c|c|c|c|}
\hline \multirow{2}{*}{$\begin{array}{l}\text { Percentage of variance accounted for } \\
\text { Significant predictors in the final } \\
\text { regression model }\end{array}$} & \multicolumn{3}{|c|}{$R=0.436, R^{2}=0.190, P<0.001$} \\
\hline & $\beta$ & $\beta(95 \% \mathrm{Cl})$ & $P$ \\
\hline Intercept & -5.116 & $-8.279,-1.954$ & 0.002 \\
\hline Sex $($ male $=0$, female $=1)$ & -0.913 & $-1.735,-0.091$ & 0.030 \\
\hline $\begin{array}{l}\text { Solitary living at the respective assessment } \\
(\text { no }=0 \text {, yes }=1 \text { ) }\end{array}$ & 2.808 & $2.001,3.616$ & $<0.001$ \\
\hline ChEl dose ${ }^{a}$ & -0.021 & $-0.039,-0.002$ & 0.030 \\
\hline Time in months from the start of ChEl therapy & 0.032 & $0.001,0.062$ & 0.041 \\
\hline MMSE score at the respective assessment & 0.133 & $0.060,0.205$ & $<0.001$ \\
\hline IADL score at the respective assessment & 0.305 & $0.199,0.412$ & $<0.001$ \\
\hline PSMS score at the respective assessment & 0.343 & $0.213,0.474$ & $<0.001$ \\
\hline Number of medications at baseline & -0.247 & $-0.372,-0.121$ & $<0.001$ \\
\hline
\end{tabular}

Notes: APOE genotype, type of ChEl agent, age at onset or at baseline, years of education, rate of change in MMSE, IADL, or PSMS scores, and the interaction term "sex $\times$ solitary living" were not significant. $\beta$ values were unstandardized and are expressed per I unit increase for continuous variables and for the condition present for dichotomous variables. aMean percentage of the maximum recommended dose, ie, $10 \mathrm{mg}$ of donepezil, $12 \mathrm{mg}$ of rivastigmine, or $24 \mathrm{mg}$ of galantamine.

Abbreviations: APOE, apolipoprotein E; ChEl, cholinesterase inhibitors; Cl, confidence interval; IADL, Instrumental Activities of Daily Living scale; MMSE, Mini-Mental State Examination; PSMS, Physical Self-Maintenance Scale.

Other strengths of the large 3-year prospective SATS study are the 6-month, well-structured, follow-up assessments of different aspects of AD progression, such as ChEI therapy, cognitive and functional abilities, and the use of formal services, which also allows the evaluation of lessinvestigated longitudinal rates of change. In most research it is rarely possible to combine formal services data on an individual level with clinical characteristics, eg, cognitive and ADL status. ${ }^{35} \mathrm{~A}$ representative group of ChEI-treated patients from memory clinics with mild to moderate $\mathrm{AD}$ and concomitant illnesses and medications was included in this study. The SATS design represents high-quality individual care on a regular basis and contact with a specific nurse by each patient, which implies continuity and security for the individual and their relatives. Hence, the SATS has developed into a clinical follow-up program that is today offered to all patients with $\mathrm{AD}$ at our clinic.

A limitation of this study was that the amount of informal care, if any, was not investigated. Almost two-thirds of the users of HHS were living alone at baseline, which implies

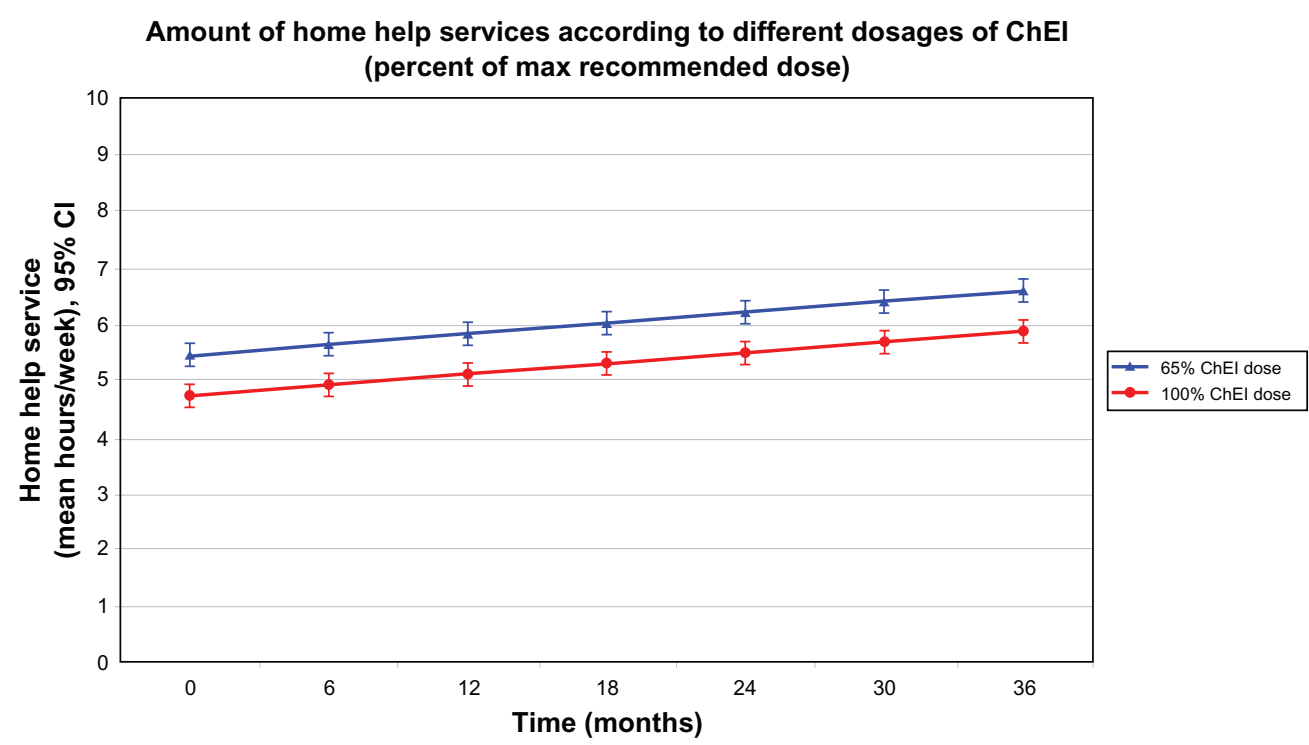

Figure 3 Three-year mean outcomes for the amount of HHS per week, with $95 \%$ confidence intervals, predicted with a multiple linear regression model according to different percentages of the maximum recommended $\mathrm{ChEl}$ dose (100\% versus the mean $65 \%$ observed in this study).

Notes: Patients taking higher doses received lower volumes of HHS $(P=0.030)$. The arbitrary example presented in the figure is based on an average solitary-living woman with an MMSE score of 2I, an IADL score of 17, and a PSMS score of 8 at the assessments and who was taking three medications at baseline.

Abbreviations: ChEl, cholinesterase inhibitor; HHS, home help services; IADL, Instrumental Activities of Daily Living scale; MMSE, Mini-Mental State Examination; PSMS, Physical Self-Maintenance Scale. 
that the provision of informal care may be limited for those individuals. Most help for cognitively impaired elderly was reported to come from relatives living in the same household. ${ }^{36}$ Furthermore, an AD study that investigated the numbers of caregiving hours allocated reported that the proportion of time provided by formal caregivers increased over time relative to the proportion of informal help. ${ }^{37}$ The presence of and time to HHS might be affected by other factors that do not originate from the patient's AD, such as concomitant somatic diseases and disabilities or the caregiver's health and situation, which were not assessed in the SATS. However, the strong sociodemographic and clinical predictors of HHS identified in the multivariate models in this study are consistent with previous work, and there is no evidence that the other significant predictors (eg, ChEI dose) would be less important if they were mediated by other factors.

This is the first study to investigate the effects of ChEIs on HHS, and more research is warranted to validate our results. To improve and extend our understanding of this issue, future studies are required to evaluate whether ChEIs have any effect on the amount of informal care made available to AD patients or on the caregiver burden. Studies are required to assess whether women with $\mathrm{AD}$ are receiving the volume of formal services they really need, according to their impairments. Furthermore, it is essential to focus on how the service providers can best identify the cognitively impaired and frail care recipients at risk of an inadequate amount of HHS and their potentially unmet needs.

\section{Conclusion}

This observational study of AD patients showed that the dose of ChEI but not the specific drug is an important predictor of both the time to and the amount of HHS. Thus, ChEI treatment might have a slowing effect on the rising costs of community-based care. The likelihood of receiving HHS was greater among women, yet they received fewer mean hours of help per week compared to men with the same level of disease severity. The perceived need for care might be influenced by the gender-role preconceptions of the service providers, suggesting for instance that cognitively impaired women might not receive the volume of home help they actually need. The deterioration in IADL abilities rather than in cognition predicted a shorter time to HHS, which demonstrates the importance of IADL follow-up in AD. Lower cognitive ability or a greater number of medications at baseline were related to fewer hours of HHS. This finding implies that the more cognitively impaired and frail elderly $\mathrm{AD}$ patients who are unable to request more help from the social services are at risk of having their needs unmet, which could precipitate institutionalization.

\section{Acknowledgments}

This work was supported by grants from Demensfonden (Dementia Foundation), Sweden, and by the Swedish Research Council (grant no 523-2010-520). The sponsors had no involvement in study design, in the collection, analysis, and interpretation of data, in the writing of the report or in the decision to submit the manuscript. We wish to thank all the patients and their relatives for their cooperation with this study. The authors are grateful to the staff of all the centers who participated in the management of the patients and provided administrative support for the study.

\section{Disclosure}

Dr Carina Wattmo has received speaker honoraria from Novartis. Dr Elisabet Londos has received speaker honoraria from Lundbeck Inc and Novartis. The authors report no other conflicts of interest in this work.

\section{References}

1. Ott A, Breteler MM, van Harskamp F, et al. Prevalence of Alzheimer's disease and vascular dementia: association with education. The Rotterdam study. BMJ. 1995;310(6985):970-973.

2. Reisberg B, Ferris SH, de Leon MJ, et al. The stage specific temporal course of Alzheimer's disease: functional and behavioral concomitants based upon cross-sectional and longitudinal observation. Prog Clin Biol Res. 1989;317:23-41.

3. Jönsson L, Eriksdotter Jönhagen M, Kilander L, et al. Determinants of costs of care for patients with Alzheimer's disease. Int $J$ Geriatr Psychiatry. 2006;21(5):449-459.

4. Lagergren M. The systems of care for frail elderly persons: the case of Sweden. Aging Clin Exp Res. 2002;14(4):252-257.

5. Wimo A. Demenssjukdomarnas Samhällskostnader och Antalet Dementa i Sverige 2005 [The Societal Costs of Dementia and the Number of Demented in Sweden 2005]. Stockholm: Socialstyrelsen (The National Board of Health and Welfare); 2007. Swedish.

6. Kadushin G. Home health care utilization: a review of the research for social work. Health Soc Work. 2004;29(3):219-244.

7. Philp I, McKee KJ, Meldrum P, et al. Community care for demented and non-demented elderly people: a comparison study of financial burden, service use, and unmet needs in family supporters. BMJ. 1995; 310(6993):1503-1506.

8. Graessel E, Luttenberger K, Bleich S, Adabbo R, Donath C. Home nursing and home help for dementia patients: predictors for utilization and expected quality from a family caregiver's point of view. Arch Gerontol Geriatr. 2011;52(2):233-238.

9. Wimo A, Sjolund BM, Skoldunger A, Johansson L, Nordberg G, von Strauss E. Incremental patterns in the amount of informal and formal care among non-demented and demented elderly persons: results from a 3-year follow-up population-based study. Int J Geriatr Psychiatry. 2011;26(1):56-64.

10. Birks J. Cholinesterase inhibitors for Alzheimer's disease. Cochrane Database Syst Rev. 2006;1:CD005593.

11. Lopez OL, Becker JT, Wisniewski S, Saxton J, Kaufer DI, DeKosky ST. Cholinesterase inhibitor treatment alters the natural history of Alzheimer's disease. J Neurol Neurosurg Psychiatry. 2002;72(3):310-314. 
12. Wattmo C, Wallin AK, Londos E, Minthon L. Risk factors for nursing home placement in Alzheimer's disease: a longitudinal study of cognition, ADL, service utilization, and cholinesterase inhibitor treatment. Gerontologist. 2011;51(1):17-27.

13. Mortimer JA, Ebbitt B, Jun SP, Finch MD. Predictors of cognitive and functional progression in patients with probable Alzheimer's disease. Neurology. 1992;42(9):1689-1696.

14. Wallin AK, Andreasen N, Eriksson S, et al. Donepezil in Alzheimer's disease: what to expect after 3 years of treatment in a routine clinical setting. Dement Geriatr Cogn Disord. 2007;23(3):150-160.

15. Folstein MF, Folstein SE, McHugh PR. "Mini-mental state". A practical method for grading the cognitive state of patients for the clinician. J Psychiatr Res. 1975;12(3):189-198.

16. Frances A, American Psychiatric Association. Diagnostic and Statistical Manual of Mental Disorders, Fourth Edition (DSM-IV). Washington, DC: American Psychiatric Association; 1994.

17. McKhann G, Drachman D, Folstein M, Katzman R, Price D, Stadlan EM. Clinical diagnosis of Alzheimer's disease: report of the NINCDSADRDA Work Group under the auspices of Department of Health and Human Services Task Force on Alzheimer's Disease. Neurology. 1984;34(7):939-944.

18. Lawton MP, Brody EM. Assessment of older people: self-maintaining and instrumental activities of daily living. Gerontologist. 1969;9(3): $179-186$

19. International Classification of Functioning, Disability and Health (ICF). [webpage on the Internet]. Geneva: World Health Organization; 2001. Available from: http://www.who.int/classifications/icf/en/. Accessed September 21, 2012.

20. Kolada [webpage on the Internet]. Kommun- och landstingsdatabasen [The Swedish Municipal and County Database]. Stockholm: Rådet för Främjande av Kommunala Analyser (RKA); 2010. Available from: http://www.kolada.se/portal.php. Accessed September 21, 2012. Swedish.

21. Raskind MA, Peskind ER, Truyen L, Kershaw P, Damaraju CV. The cognitive benefits of galantamine are sustained for at least 36 months: a long-term extension trial. Arch Neurol. 2004;61(2):252-256.

22. Small GW, Kaufer D, Mendiondo MS, Quarg P, Spiegel R. Cognitive performance in Alzheimer's disease patients receiving rivastigmine for up to 5 years. Int J Clin Pract. 2005;59(4):473-477.

23. Winblad B, Wimo A, Engedal K, et al. 3-year study of donepezil therapy in Alzheimer's disease: effects of early and continuous therapy. Dement Geriatr Cogn Disord. 2006;21(5-6):353-363.

24. Wattmo C, Wallin AK, Londos E, Minthon L. Long-term outcome and prediction models of activities of daily living in Alzheimer disease with cholinesterase inhibitor treatment. Alzheimer Dis Assoc Disord. 2011;25(1):63-72.
25. Geldmacher DS, Provenzano G, McRae T, Mastey V, Ieni JR. Donepezil is associated with delayed nursing home placement in patients with Alzheimer's disease. J Am Geriatr Soc. 2003;51(7):937-944.

26. Courtney C, Farrell D, Gray R, et al. Long-term donepezil treatment in 565 patients with Alzheimer's disease (AD2000): randomised doubleblind trial. Lancet. 2004;363(9427):2105-2115.

27. Forbes DA, Jansen SL, Markle-Reid M, et al. Gender differences in use and availability of home and community-based services for people with dementia. Can J Nurs Res. Mar 2008;40(1):39-59.

28. Bass DM, Looman WJ, Ehrlich P. Predicting the volume of health and social services: integrating cognitive impairment into the modified Andersen framework. Gerontologist. 1992;32(1):33-43.

29. Doty P, Jackson ME, Crown W. The impact of female caregivers' employment status on patterns of formal and informal eldercare. Gerontologist. 1998;38(3):331-341.

30. Heyman A, Peterson B, Fillenbaum G, Pieper C. Predictors of time to institutionalization of patients with Alzheimer's disease: the CERAD experience, part XVII. Neurology. 1997;48(5):1304-1309.

31. Hatoum HT, Thomas SK, Lin SJ, Lane R, Bullock R. Predicting time to nursing home placement based on activities of daily living scores a modelling analysis using data on Alzheimer's disease patients receiving rivastigmine or donepezil. J Med Econ. 2009;12(2):98-103.

32. Hawranik P. The role of cognitive status in the use of inhome services: implications for nursing assessment. Can J Nurs Res. 1998;30(2): 45-65.

33. Penning MJ. Cognitive impairment, caregiver burden, and the utilization of home health services. J Aging Health. 1995;7(2):233-253.

34. Johansson L, Sundstrom G, Hassing LB. State provision down, offspring's up: the reverse substitution of old-age care in Sweden. Ageing Soc. 2003;23(03):269-280.

35. Nordberg G, von Strauss E, Kareholt I, Johansson L, Wimo A. The amount of informal and formal care among non-demented and demented elderly persons-results from a Swedish population-based study. Int $J$ Geriatr Psychiatry. 2005;20(9):862-871.

36. Wenger GC, Burholt V, Scott A. Dementia and help with household tasks: a comparison of cases and non-cases. Health Place. 1998;4(1): 33-44.

37. Feldman HH, Van Baelen B, Kavanagh SM, Torfs KE. Cognition, function, and caregiving time patterns in patients with mild-to-moderate Alzheimer disease: a 12-month analysis. Alzheimer Dis Assoc Disord. 2005;19(1): 29-36
Clinical Interventions in Aging

\section{Publish your work in this journal}

Clinical Interventions in Aging is an international, peer-reviewed journal focusing on evidence-based reports on the value or lack thereof of treatments intended to prevent or delay the onset of maladaptive correlates of aging in human beings. This journal is indexed on PubMed Central, MedLine, the American Chemical Society's 'Chemical Abstracts Ser-

\section{Dovepress}

vice' (CAS), Scopus and the Elsevier Bibliographic databases. The manuscript management system is completely online and includes a very quick and fair peer-review system, which is all easy to use. Visit http://www.dovepress.com/testimonials.php to read real quotes from published authors. 